\title{
A COCULPABILIDADE PENAL COMO CIRCUNSTÂNCIA ATENUANTE GENÉRICA DO ART. 66 DO CÓDIGO PENAL
}

Alyne Hayanne da Silva

Ex-membra do Programa Motyrum de Educação Popular Em Direitos Humanos. Ex-membra do Corpo Editorial da Revista Transgressões. Graduanda em Direito pela Universidade Federal do Rio Grande do Norte (UFRN).

E-mail: alyne_hayanne@yahoo.com.br

Marcos Rangeli da Silva

Graduando em Direito pela Universidade Federal do Rio Grande do Norte (UFRN).

E-mail: markos.messenger@hotmail.com

\section{RESUMO}

Apresenta-se neste trabalho o estudo sobre o que o Princípio da Coculpabilidade Social, assim como o porquê deste ser importante para garantir a efetividade do Princípio da Igualdade consagrado no artigo 5으 Constituição Federal de 1988. Por fim, analisaremos a possibilidade da coculpabilidade social ser aplicada como circunstância atenuante genética do art. 66 do Código Penal brasileiro.

Palavras-chave: Princípio da Igualdade. Princípio da Coculpabilidade Social. Circunstância atenuante inominada. 


\section{INTRODUÇÃO}

A Constituição Federal de 1988 trouxe em seu artigo $5^{\circ}$ diversos princípios, entre eles o princípio da igualdade, que busca conferir tratamento isonômico a todos perante os processos de criação e aplicação das leis, assim como não permitir tratamento discriminatório, racista, sexista, entre outros, nas relações particulares regidas pelo direito.

Entretanto, o percebeu-se que o princípio da igualdade não busca simplesmente que todos sejam tratados igualmente, pois tal entendimento poderia acentuar ainda mais as desigualdades. Assim, viu-se que para se respeitar o este princípio, seria necessário que levássemos em consideração as desigualdades já existentes, tratando de forma desigual os desiguais na medida de suas desigualdades.

Este princípio é demasiadamente importante na esfera penal, pois garante penalidades mais justas face aos crimes cometidos a partir da individualização das penas. Entretanto, as penas são realmente individualizadas? A análise das circunstâncias fáticas no cometimento do crime é suficiente para garantir a igualdade na aplicação e execução das penas? Haveriam elementos externos capazes de influenciar seres humanos ao cometimento de crimes que não estejam diretamente ligados ao caso concreto? Tais elementos externos devem ser considerados no momento da aplicação e execução das penas? O que é, e como o Princípio da Coculpabilidade social se encaixaria neste contexto? Estas são as indagações a serem respondidas no desenvolvimento deste trabalho.

\section{O QUE SÃO PRINCÍPIOS E QUAL O SEU PAPEL NO ORDENAMENTO JURÍDICO BRASILEIRO}

Primeiramente, para sermos capazes de entender a importância e a aplicação do Princípio da Coculpabilidade social no ordenamento jurídico brasileiro, é necessário entender o que são os princípios.

Assim, princípios podem ser definidos como sendo "ideias centrais de um sistema, ao qual dão sentido lógico, harmonioso, racional, permitindo a compreensão de seu modo de se organizar-se". 
Segundo (GUERRA FILHO, 2002, P. 17) “Os princípios devem ser entendidos como indicadores de uma opção pelo favorecimento de determinado valor, a ser levada em conta na apreciação jurídica de uma infinidade de fatos e situações possíveis". Além disso, o autor ainda afirma que existem princípios jurídicos fundamentais, que são dotados também de dimensão ética e política, assim, apontam a direção que se deve ser seguida no momento em que estivermos tratando de qualquer fato que ocorrer de acordo com as normas que estejam em vigor em nosso ordenamento.

Para Rosenvald os princípios não seriam apenas leis,

mas o próprio direito em toda a sua extensão e abrangência. Da positividade dos textos constitucionais alcançam a esfera decisória dos arestos, constituindo uma jurisprudência de valores que determina o constitucionalismo contemporâneo, a ponto de fundamentar uma nova hermenêutica dos tribunais (ROSENVALD, 2005, P. 45-46).

(BERTONCINI, 2002, P. 33-34) ainda esclarece que o caráter normativo dos Princípios passou por um lento processo de evolução doutrinária, passando por três fases: a jusnaturalista, a juspositivista e a pós-positivista. Nas quais as duas primeiras fases não conferiam a natureza normativa a estes.

De forma sucinta, ainda de acordo com o autor supracitado, pode-se dizer que na primeira fase os princípios funcionariam como sendo o alicerce do Direito, servindo como uma forma de inspiração, sendo, assim, quase que desprovidos de normatividade. No segundo estágio, estes passam a ser positivados ou juspositivados, tornando-se "fontes normativas subsidiárias", derivando da lei e tendo por finalidade servir-lhe como fonte secundária e subsidiária, buscando impedir lacunas. Por fim, temos a fase pós-positivista, ao qual passe-se a reconhecer o caráter normativo dos princípios:

\footnotetext{
A normatividade dos princípios [...] foi afirmada precursoramente em 1952 por Crisafulli. [...] Afirma Crisafulli a dupla eficácia dos princípios - imediata e mediata (programática) -, asseverando tratar-se de normas a certas condutas publicistas ou mesmo particulares. Reconhece que essa espécie normativa tanto pode ser expressa no ordenamento jurídico como pode ser implícita, desempenhando relevante papel na interpretação do Direito. É fonte axiológica da qual derivam normas particulares e, por um outro prisma, norma a que se pode chegar através de um processo inverso, de generalização. Portanto, da regra particular até chegar-se ao vetor principiológico. Crisafulli, sem dúvida desempenhou papel fundamental na elaboração da doutrina da normatividade dos princípios.” (BERTONCINI, 202, P.36).
}

Para o doutrinador Miguel Reale 
Princípios são, pois, verdades ou juízos fundamentais, que servem de alicerce ou de garantia de certeza a um conjunto de juízos, ordenados em um sistema de conceitos relativos a dada porção da realidade. Às vezes também se denominam princípios certas proposições que, apesar de não serem evidentes ou resultantes de evidências, são assumidas como fundantes da validez de um sistema particular de conhecimentos, como seus pressupostos necessários. (REALE apud SILVA, 2003, P. 1).

No ordenamento jurídico brasileiro os princípios ganharam força com o advento da Constituição Federal de 1988, que traz Princípios Constitucionais, como o Princípio da Igualdade, que será explorado mais a frente. Neste sentido entende (NEGREIROS apud PRETEL, 2009, P. 1) que seriam os princípios guias, devendo ser considerados como forma de orientação, sendo assim normas que são providas de um elevado grau de generalidade e indeterminação, tendo hierarquia elevada em relação as regras, sendo assim valores que são essenciais para a perpetuação do Estado de Direito.

\section{PRINCÍPIO DA IGUALDADE NA CONSTITUIÇÃO FEDERAL}

A Constituição Federal de 1988, traz no caput de seu artigo $5^{\circ}$ vários princípios, dentre os quais encontra-se o princípio da igualdade, nos seguintes termos:

\footnotetext{
Artigo $5^{\circ}$. Todos são iguais perante a lei, sem distinção de qualquer natureza, garantindo-se aos brasileiros e aos estrangeiros residentes no País a inviolabilidade do direito à vida, à liberdade, à igualdade, à segurança e à propriedade, nos termos seguintes.
}

Assim, o princípio da igualdade introduzido no artigo $5^{\circ}$ da $\mathrm{CF} / 88$ prevê que deve haver igualdade de aptidões e possibilidades dos cidadãos, devendo todos gozarem de isonomia perante a lei, sendo vedada qualquer discriminação arbitrária ou absurda. Desta forma, os princípios limitam a atuação do poder legislativo, dos intérpretes das leis, das autoridades públicas e do particular.

$\mathrm{O}$ artigo $5^{\circ}$ não é o único da Constituição Federal que versa sobre a igualdade. Além do Inciso XXXVIII do artigo supracitado, que versa sobre a igualda de jurisdicional, o art. $7^{\circ}$, inciso XXXII fala sobre a igualdade trabalhista, o art. 14 dispõe acerca da igualdade política e, finalmente, o inciso III do art. 150 traz a igualdade tributária. Assim, percebe-se que o princípio da igualdade atua em diversas vertentes e, como tal, atua também na esfera penal. 
O princípio da igualdade opera tanto frente ao legislador quanto perante ao poder executivo, impedindo tanto a criação de leis que firam a isonomia como interpretações de regras que tragam um tratamento desigual injustificado.

Assim, (MORAES, 2002, p. 65) afirma que o princípio da igualdade limita o poder do legislador ou do próprio Poder Executivo, na edição, respectivamente, de leis, atos normativos e medidas provisórias, impedindo que haja tratamentos abusivamente diferenciados a pessoas que possuem uma situação idêntica. Por outro lado, quanto ao intérprete, este fica obrigado a aplicar as leis e atos normativos de forma isonômica, sem que exista discriminação em razão de sexo, religião, convicções filosóficas ou políticas, raça ou classe social, evitando, assim, tratamentos sexistas, racistas, discriminatórios, entre outros.

Entretanto, mesmo sendo vedado o tratamento desigual injustificado ou absurdo, entende-se que é possível haver um cuidado diferenciado, desde que este seja autorizado pela Constituição Federal, a qual elenca as exceções.

Assim, o Princípio da Igualdade pressupõe que as pessoas em situações iguais devem ser vistas de forma isonômica, entretanto, havendo desigualdade em relação a elas e desde que o disciplinamento equânime nesta situação possa acentuar ainda mais estas diferenças, estas pessoas devem ser tratadas de forma desigual para garantir a igualdade. Nesta mesma linha ensina (NERY JÚNIOR, 1999, P. 42) que "dar tratamento isonômico às partes significa tratar igualmente os iguais e desigualmente os desiguais, na exata medida de suas desigualdades".

\section{PRINCÍPIO DA COCULPABILIDADE SOCIAL}

Primeiramente, para explicar o que é a coculpabilidade social precisamos entender de onde surgiu a coculpabilidade. Não há de discordar que na sociedade atual há grupos sociais que possuem certos privilégios em detrimento de outros grupos, como acesso a educação de qualidade, acesso a saúde, saneamento básico, entre outros. Desta forma, surgem medidas afirmativas na tentativa de diminuir a discriminação entre esses grupos, como bolsas de estudo e cotas, já que se tratarmos os indivíduos pertencentes a ambos os grupos de forma igualitária apenas acentuaremos as diferenças, como, por exemplo, quando um aluno de escola particular concorre diretamente com um aluno de 
uma escola pública por uma vaga em uma Universidade Federal, assim, as cotas buscam diminuir o abismo existente entre essas realidades.

A Constituição Federal de 1988 elencou o acesso a saúde, educação e condições dignas para todos os cidadãos, independentemente de classe social, cor, sexo, orientação sexual, etc. Entretanto, há pessoas que não possuem acesso à educação, a saúde, a condições dignas de sobrevivência, trabalho, e são privados de vários outros direitos fundamentais. É possível, então, dizer que estas pessoas possuem a mesma consciência ética, social e de justiça do que alguém que nunca teve os seus direitos básicos fundamentais privados? A resposta só pode ser negativa.

A partir da explanação feita no parágrafo anterior, percebemos que estes sujeitos de pronto não possuem tratamento igual perante o Estado, já que uns possuem condições dignas e outras não. Sendo o Estado o responsável por providenciar que tais direitos sejam respeitados, e ao permitir que um cidadão passe fome, adoeça e não tenha acesso a um tratamento adequado, trabalhe em condições análogas a de escravo, não teria o Estado parcela de culpa em relação as decisões feitas por este indivíduo e que poderiam ser evitadas se ele possuísse melhores condições de vida? Assim surgiria a coculpabilidade do Estado, sendo responsável juntamente com indivíduos de determinados grupos no cometimento de certos crimes.

Assim entende (SANTOS apud GOMES; SILVA, 2009, P. 1) que de acordo segundo o Princípio da Coculpabilidade, indivíduos pertencentes a determinadas classes sociais, ao cometerem certos tipos de crimes, não devem ser os únicos a serem responsabilizados pelo ato, haja vista que não seriam os únicos responsáveis por ele, devendo o Estado também ser responsabilizado, pois possui inegável parcela de culpa. Isto ocorre principalmente quando há crime cometido tento como prima ratio elementos de natureza social, sendo a ausência de condições mínimas que garantam a dignidade humana de cada cidadão um dos principais motivadores.

Assim, o fato de haver diferenciação em relação ao acesso a educação, saúde, lazer, moradia, alimentação, segurança e emprego, pode ser levado em consideração pelo magistrado ao se aplicar a pena, na fixação da pena base ou ao aplicar uma atenuante inominada, em razão de sua capacidade de influenciar na capacidade de autodeterminação e da consciência em relação a reprovabilidade social daquela conduta em questão. Sobre este ponto, (ZAFARONI; PIERRANGELI apud GRECO) se posicionam da seguinte maneira: 
Todos sujeitos agem numa inconstância dada e com um âmbito de autodeterminação também dado. Em sua própria personalidade há uma contribuição para este âmbito de autodeterminação, posto que a sociedade por melhor organizada que seja - nunca tem a personalidade de brincar a todos os homens com as mesmas oportunidades. Em consequência, há sujeitos que desta maneira por causas sociais. Não será possível atribuir estas causas sociais ao sujeito e sobrecarrega-lo com elas no momento da reprovação de culpabilidade. Costuma-se dizer que há uma "coculpabilidade", com a qual a própria sociedade deve arcar (ZAFARONI; PIERRANGELI apud GRECO, 2010, P. 404).

Desta forma, temos que o Princípio da Coculpabilidade nada mais é do que atribuir ao Estado e a sociedade como a parcela de culpa que lhes cabem razão da privação de direitos básicos necessários a dignidade da pessoa humana a determinada parcela da população.

\subsection{A relação entre o Princípio da Igualdade e o Princípio da Coculpabilidade}

A partir do que foi explanado na seção 3, chega-se à conclusão de que o princípio da igualdade busca trazer um equilíbrio ao ordenamento jurídico brasileiro, não permitindo práticas e comportamento que acentuem discriminações a grupos desfavorecidos da sociedade. Desta forma, é necessário que não se trate igualmente todos quando houver diferença entre os grupos, como por exemplo a cobrança de impostos de forma proporcional a renda, como é o caso do Imposto de Renda Sobre Pessoa Física, ou ao tamanho do imóvel, como é o caso do IPTU. Ao analisarmos o direito penal, isto também ocorre em relação a aplicação e execução das penas, a existência de atenuantes e majorantes entre outros.

Desta forma, como o Princípio da Igualdade estaria relacionado ao Princípio da Coculpabilidade social? Chega-se à conclusão de que se existe responsabilidade do Estado e da sociedade em relação ao cometimento de determinados crimes, como por exemplo aquele que passaram a cometer crimes por influência de outros traficantes da favela onde mora pois estes lhe ofereceram comida, trabalho e proveram a educação de seus filhos, por exemplo. Neste caso, houve falha por parte do Estado em oferecer educação, saúde, alimentação aquele indivíduo, sendo tais necessidades saciadas por intermédio de um traficante que traz a ilusão de segurança e de dignidade. Assim, o grau 
de reprovabilidade da conduta deste cidadão seria menor do que a de um traficante que veio de família abastada e teve acesso a educação e saúde.

No exemplo supracitado o atual entendimento acerca do que seria o Princípio da Igualdade consagrado na Constituição Federal de 1988, permitiu que fosse aplicado um tratamento diferenciado entre os dois sujeitos que cometeram o mesmo crime, pois um teria acesso a condições que, em tese, o impediriam de cometer aquele crime pois teria total consciência da reprovabilidade daqueles atos, enquanto o outro foi levado pelas privações sofridas a seguir aquele caminho, não sendo possível que este tivesse total consciência da reprovabilidade dos atos cometidos, pois o Estado e a sociedade também falharam com ele.

\section{O PRINCÍPIO DA COCULPABILIDADE SOCIAL E O PRINCÍPIO DA INDIVIDUALIZAÇÃO DA PENA}

Dentro da ótica constitucional, pode-se vislumbrar ainda o Princípio da Coculpabilidade social como consectário do Princípio da Individualização da Pena, o qual encontra sede constitucional no art. $5^{\circ}$, incisos XLV e XLVI, da Constituição Federal de 1988.

Segundo leciona o eminente doutrinador (NUCCI, 2014):

\footnotetext{
"A individualização da pena tem o significado de eleger a justa sanção penal, quanto ao montante, ao perfil e aos efeitos pendentes sobre o sentenciado, tornando-o único e distinto dos demais infratores, ainda que coautores ou mesmo corréus. Sua finalidade e importância é a fuga da padronização da pena, da 'mecanizada' ou 'computadorizada' aplicação da sanção penal, prescindindo da figura do juiz, como ser pensante, adotando-se em seu lugar qualquer programa ou método que leve à pena preestabelecida, segundo um modelo unificado, empobrecido e, sem dúvida, injusto.” (NUCCI, 2014, P. 25)
}

Desse modo, pode-se concluir que o Princípio da Individualização da pena possui por escopo a máxima adequação da pena ao agente infrator na medida de sua conduta e de sua culpabilidade, servindo ao agente como uma garantia contra aplicação da pena de forma padronizada, sem a necessária análise das circunstâncias fáticas que envolvem a conduta delituosa e sua correlação com a pena aplicada.

A individualização da pena insere-se nas três fases da pena, ou seja, na cominação, aplicação e execução, as quais serão analisadas a seguir. 
A cominação da pena ocorre no momento em que o legislador, segundo um critério político, seleciona os bens jurídicos mais importantes da sociedade os quais passarão a ser tutelados pelo Direito Penal. Assim, na elaboração do tipo penal incriminador, diante da importância do bem jurídico envolvido, o legislador fixará as penas mínima e máxima que sejam suficientes e necessárias à reprovação e prevenção do crime. Não por outro motivo é que os crimes atentatórios aos bens jurídicos mais caros à sociedade, como a vida por exemplo, possuem reprimenda mais severa do que outros delitos. Eis a individualização legislativa.

De outro norte, a individualização da pena se evidencia também no momento da aplicação da pena, ou seja, após a ocorrência do delito, na qual atuará o Juiz na fixação da pena em concreto, atentando para as circunstâncias judiciais, atenuantes e agravantes, causas de aumento e de diminuição da pena aplicáveis ao caso concreto. Esta é a individualização judiciária.

Por fim, a individualização da pena encontra espaço também na execução da pena, fase na qual o Juiz deverá individualizar o cumprimento da sanção aplicada, levando-se em consideração os antecedentes e a personalidade do condenado, nos termos do que preceitua o art. $5^{\circ}$ da Lei de Execução Penal (Lei n ${ }^{\circ}$ 7.210/84).

Desse modo, tanto o legislador, quando da cominação da pena em abstrato, quanto o magistrado, na aplicação e na execução da pena, devem atentar aos aspectos individual e subjetivo do infrator.

Sob a ótica do Princípio da Coculpabilidade Social, a individualização da pena passa necessariamente pela consideração de fatores socioeconômicos nas fases da pena, de modo a punir de forma menos severa aqueles indivíduos que não tiveram as mesmas chances e oportunidades na vida que os demais, sob pena de ser o agente punido de forma mais severa. Ora, não se afigura justo, por exemplo, que seja aplicada a mesma pena pelo cometimento de um ilícito penal a um indivíduo que vive em estado de miserabilidade e não teve acesso à educação e ao indivíduo de boas condições financeiras e que teve amplas oportunidade de estudo e trabalho, mas não as aproveitou.

Assim, a aplicação de uma pena justa e individualizada passa necessariamente pelo reconhecimento das condições sociais e pessoais do infrator, de modo a tornar efetivo o Princípio da Individualização da Pena. 


\section{A POSSIBILIDADE DE APLICAÇÃO DA COCULPABILIDADE COMO CIRCUNSTÂNCIA ATENUANTE INOMINADA DO ART. 66 DO CÓDIGO PENAL}

Ab initio, faz-se mister ressaltar que a aplicação da coculpabilidade social não encontra previsão expressa na legislação penal ou processual penal brasileira. No entanto, a despeito de não ter sido positivada, a análise da atual legislação pertinente permite vislumbrar a possibilidade de sua aplicação pelo magistrado como circunstância atenuante inominada, consoante disposição constante no art. 66 do Código Penal, como será melhor exposto a seguir.

Como é cediço, o art. 65 do Código Penal Brasileiro prevê de forma expressa as circunstâncias gerais que atenuam a pena do infrator, quando presentes no caso concreto. Por seu turno, o art. 66 do mesmo diploma, abre a possibilidade de a pena ser atenuada em razão de circunstância relevante, anterior ou posterior ao crime, mesmo que não prevista expressamente em lei.

Nessa toada, vozes na doutrina passaram a defender a possibilidade de aplicação da coculpabilidade como uma circunstância atenuante inominada, com fulcro no art. 66 do Código Penal, destacadamente os doutrinadores (ZAFFARONI; PIERANGELI, 2011):

\footnotetext{
"Uma circunstância que, lamentavelmente, o texto vigente não menciona de maneira expressa, mas que pode ser considerada por esta via de atenuantes, é a menor culpabilidade do agente proveniente do que se costumou chamar de 'co-culpabilidade' (ver n. 353). É sabido que, por óbvias razões, que até o presente momento nenhum sistema político no mundo conseguiu superar, os habitantes dispõem de distintas margens sociais de autonomia ou de distinto espaço social, em razão das desigualdades socioeconômicas, de instrução etc., isto é, existem pessoas que dispõem de meios econômicos e de graus de instrução superiores aos dos outros, estes, frequentemente, em graus de carência bem marcados. O princípio acerca disto está em que, se a sociedade outorga, ou permite a alguns, gozar de espaços sociais dos quais outros não dispõem ou são a estes negados, a reprovação de culpabilidade que se faz à pessoa a quem se tem negado as possibilidades outorgadas a outras, deve ser em parte compensada, isto é, a sociedade deve arcar com uma parte da reprovação, pois não pode creditar ao agente uma maior possibilidade de motivar-se numa norma, cujo conhecimento não lhe possibilitou. Isto leva a considerar, necessariamente, como atenuante, a humilde condição social de uma pessoa, suas carências econômicas e de instrução, seu escasso acesso à medicina preventiva e curativa, e, no geral, o menor gozo dos direitos sociais, sempre e quando estas circunstâncias não cheguem a um grau tal que devam ser consideradas como presença de uma eximente, em razão do estado de necessidade justificante ou exculpante". (ZAFFARONI; PIERANGELI, 2011, P. 715-716).
} 
Compartilha do mesmo pensamento os autores (CARVALHO; CARVALHO, 2008):

\begin{abstract}
A precária situação econômica do imputado deve ser priorizada como circunstância atenuante obrigatória no momento da cominação da pena. Apesar de não estar prevista no rol de circunstâncias atenuantes do art. 65 do Código Penal brasileiro, a norma do art. 66 possibilita a recepção do princípio da coculpabilidade, pois demonstra o caráter não taxativo das causas de atenuação. O Código Penal, ao permitir a diminuição da pena em razão de "circunstância relevante" anterior ou posterior ao crime, embora não prevista em lei, já fornece um mecanismo para a implementação deste instrumento de igualização e justiça social. (CARVALHO; CARVALHO, 2008, P. 74)
\end{abstract}

Merece destaque ainda, as modificações realizadas no Código de Processo Penal pela Lei $\mathrm{n}^{\circ} 10.792 / 2003$, no que concerne a inserção do parágrafo primeiro do art. 187 do referido diploma, o qual possui a seguinte redação:

\begin{abstract}
Art. 187. O interrogatório será constituído de duas partes: sobre a pessoa do acusado e sobre os fatos. (Redação dada pela Lei $\mathrm{n}^{\circ} 10.792$, de $1^{\circ} .12 .2003$ ) $\S 1$ o Na primeira parte o interrogando será perguntado sobre a residência, meios de vida ou profissão, oportunidades sociais, lugar onde exerce a sua atividade, vida pregressa, notadamente se foi preso ou processado alguma vez e, em caso afirmativo, qual o juízo do processo, se houve suspensão condicional ou condenação, qual a pena imposta, se a cumpriu e outros dados familiares e sociais.
\end{abstract}

Estabeleceu-se, assim, que a primeira parte do interrogatório do réu terá por objeto a pessoa do acusado, o qual será inquirido a respeito de seus meios de vida ou profissão, oportunidades sociais, entre outras coisas.

Desse modo, com a inserção do referido parágrafo, o julgador passou a contar com as informações necessários à valoração da coculpabilidade no caso concreto, na hipótese de, a partir das respostas dadas pelo acusado, o magistrado se convença de que o acusado vive em situação de miserabilidade e exclusão social.

Há, no entanto, vozes dissonantes na doutrina, a exemplo de (NUCCI, 2014) ao afirmar que "ainda que se possa concluir que o Estado deixa de prestar a devida assistência à sociedade, não é por isso que nasce qualquer justificativa ou amparo para o cometimento de delitos, implicando em fator de atenuação de pena" (NUCCI, 2014, P. 243).

Ousamos discordar do iminente doutrinador supracitado, uma vez que a coculpabilidade não se revela como uma justificativa ou amparo para o cometimento de crimes, mas, como bem expôs (ZAFFARONI; PIERANGELI, 2008) constitui uma 
compensação da reprovabilidade da conduta do infrator de acordo com a sua condição social e suas possibilidades. Assim, tendo em vista que vivemos em uma sociedade extremamente desigual, na qual poucos tem acesso a tudo e a grande maioria da população, sobretudo a de baixa renda, é privada do acesso à direitos básicos, a sociedade deve suportar uma parte de sua culpabilidade em razão das possibilidades sonegadas àquele que agiu contrariamente ao direito.

\section{APLICAÇÃO DO PRINCÍPIO DA COCULPABILIDADE NOS TRIBUNAIS BRASILEIROS}

O presente tópico tem por escopo a análise da jurisprudência dos tribunais brasileiro no tocante à aplicação da coculpabilidade. Malgrado o entendimento defendido na presente pesquisa, o Poder Judiciário tem negado aplicação à coculpabilidade pelas mais diversas razões, ora por não ter sido positivada em nosso ordenamento jurídico, ora por entende-la erroneamente como uma justificativa para o cometimento de crimes. Nesse sentido é a atual jurisprudência do Superior Tribunal de Justiça:

HABEAS CORPUS. TRÁFICO DE DROGAS. CONDENAÇÃO. APELAÇÃO JULGADA.PRETENSÕES DE ABSOLVIÇÃO E DESCLASSIFICAÇÃO. VIA INADEQUADA. EXAMEAPROFUNDADO DAS PROVAS. TEORIA DA CO-CULPABILIDADE DO ESTADO. NÃO CONFIGURAÇÃO. ORDEM DENEGADA. 1. Hipótese em que as instâncias originárias examinaram, com profundidade, os elementos de convicção produzidos nos autos da ação penal, concluindo pela condenação do paciente. Inviável atender a pretensão defensiva, de absolvição ou desclassificação da conduta, nesta via estreita do mandamus, em que vedado o revolvimento fático-probatório. 2. O Superior Tribunal de Justiça não tem admitido a aplicação da teoria da co-culpabilidade do Estado como justificativa para a prática de delitos. Ademais, conforme ressaltou a Corte estadual, sequer restou demonstrado ter sido o paciente prejudicado por suas condições sociais. 3 . Habeas corpus denegado. (STJ - HC: 187132 MG 2010/0185087-8, Relator: Ministra MARIA THEREZA DE ASSIS MOURA, Data de Julgamento: 05/02/2013, T6 - SEXTA TURMA, Data de Publicação: DJe 18/02/2013)

Na mesma esteira, seguem os Tribunais de Justiça estaduais:

APELAÇÃO CRIMINAL - TENTATIVA DE FURTO - PRINCÍPIO DA INSIGNIFICÂNCIA - ABSOLVIÇÃO - IMPOSSIBILIDADE ATENUANTE DA CO-CULPABILIDADE - INVIABILIDADE. 1. A aplicação do princípio da insignificância deve ser reservada para casos excepcionais, nos quais, além da ínfima lesão ao bem jurídico tutelado, deve ser analisado o grau de reprovação da conduta e os antecedentes do acusado. A reincidência do réu impede a aplicação do princípio da insignificância. 2. 
Não há como se responsabilizar o Estado ou a sociedade pela prática delitiva do agente, sob pena de se fomentar a criminalidade, não sendo viável, portanto, o reconhecimento da atenuante genérica da co-culpabilidade. (TJ-MG - APR: 10153130027623001 MG, Relator: Denise Pinho da Costa Val, Data de Julgamento: 29/04/2014, Câmaras Criminais / 6ª CÂMARA CRIMINAL, Data de Publicação: 08/05/2014)

APELAÇÃO-CRIME. HOMICÍDIO DOLOSO. MINORAÇÃO DO APENAMENTO ARBITRADO. AFASTAMENTO DA AGRAVANTE DA REINCIDÊNCIA. PRETENSÃO AO RECONHECIMENTO DA ATENUANTE GENÉRICA PELA CO-CULPABILIDADE DO ESTADO. 1. Verificando a existência de uma circunstância judicial desfavorável ao acusado, o apenamento arbitrado pelo juízo a quo mostrou-se excessivo, sendo impositivo o redimensionamento da pena. 2. A agravante genérica da reincidência foi declarada constitucional pelo STF, não subsistindo a tese de que configura inaceitável bis in idem. 3. Não se pode responsabilizar o Estado e a sociedade como um todo pelas escolhas de um indivíduo, não se mostrando razoável a atenuação da pena por uma eventual co-culpabilidade do Estado. RECURSO PARCIALMENTE PROVIDO. (Apelação Crime $\mathrm{N}^{\circ}$ 70058144197, Terceira Câmara Criminal, Tribunal de Justiça do RS, Relator: Fabio Vieira Heerdt, Julgado em 07/08/2014) (TJ-RS - ACR: 70058144197 RS, Relator: Fabio Vieira Heerdt, Data de Julgamento: 07/08/2014, Terceira Câmara Criminal, Data de Publicação: Diário da Justiça do dia 17/09/2014)

Ademais, percebe-se que o assunto ainda é pouco explorado no Poder Judiciário, o qual tem evitado analisar mais amplamente a temática, se limitando a repelir a aplicação da coculpabilidade por meio de argumentos simplórios e mecânicos. No entanto, a questão se revela complexa e merece uma melhor abordagem pelos operadores do direito, a exemplo do que vem ocorrendo na doutrina, a qual vem se debruçando sobre o tema e cada vez mais vem defendendo a sua aplicação.

\section{CONCLUSÃO}

A partir de todo o exposto, é possível concluir que o Princípio da Coculpabilidade Social possui uma forte base constitucional, podendo ser considerado como um preceito constitucional implícito, dada a sua direta correlação com outros igualmente previstos no texto maior, tais com os Princípios da Dignidade da Pessoa Humana, da Igualdade e da Individualização da Pena.

Noutro pórtico, voltando-se os olhos para a legislação penal e processual penal brasileira, malgrado a coculpabilidade não tenha sido expressamente positivada, observase que o art. 66 do Código Penal concedeu certa margem de liberdade ao magistrado para atenuar a pena do acusado na presença de circunstância relevante, mesmo que não conste expressamente no texto legal. 
Além disso, com a inclusão do parágrafo primeiro do art. 187 do Código de Processo Penal, o qual preceitua que a primeira parte do interrogatório do réu será composto por perguntas sobre as condições sociais do acusado, o magistrado passou a dispor das informações necessárias para a valoração da coculpabilidade no caso concreto.

Desse modo, em se constatando que o réu vive em condição de miserabilidade e privação de direitos e oportunidades, poderá o julgador aplicar a coculpabilidade, sobretudo em homenagem aos princípios da Dignidade da Pessoa Humana, da igualdade e da individualização da pena, suas principais raízes constitucionais.

Salienta-se, por fim, que não obstante a positivação da coculpabilidade seja uma condição importante para a sua aplicação, em nome da segurança jurídica e até para que a sua observância seja cogente, o fato de o legislador ter se omitido quanto a sua previsão expressa não pode servir de pretexto para o julgador também ignorá-lo, ainda mais diante dos princípios constitucionais e das disposições penais e processuais penais supramencionadas, as quais apresentam o substrato normativo necessário para a sua aplicação ao caso concreto.

\section{REFERÊNCIAS}

BERTONCINI, Mateus Eduardo Siqueira Nunes. Princípios de Direito Administrativo Brasileiro. 1. ed. São Paulo: Malheiros, 2002.

BRASIL. Constituição Federal de 1988. Promulgada em 5 de outubro de 1988. Disponível em <http://www.planalto.gov.br/ccivil_03/constituicao/ConstituicaoCompilado.htm>. Acesso em: 01 mar. 2016.

CARvalHO, Aníbal Bueno de; CARVAlHO, Salo de. Aplicação da pena e garantismo. 4. ed. Rio de Janeiro: Lúmen Juris, 2008

GRECO, Rogério. Curso de Direito Penal: Parte Geral. 12. ed. Niterói: Impetus, 2010.

GUERRA FILHO, Willis Santiago. Da interpretação especificamente constitucional. Revista de Informação Legislativa. n. 32, 1995 
NUCCI, Guilherme de Souza. Código penal comentado. 11. ed. São Paulo: Revista dos Tribunais, 2012.

NUCCI, Guilherme de Souza. Individualização da pena. 6. ed. Rio de Janeiro: Forense, 2014.

PRETEL, Mariana Pretel e. Princípios constitucionais: conceito, distinções e aplicabilidade. 26 mar. 2009. Disponível em: http://conteudojuridico.com.br/artigo,principios-constitucionais-conceito-distincoes-eaplicabilidade,23507.html>. Acesso em: 08 mar. 2016.

ROSENVALD, Nelson. Dignidade humana e boa-fé no Código Civil. 1. ed. São Paulo: Saraiva, 2005.

SANTOS, Larissa Linhares Vilas Boas. O Princípio da Igualdade. In: Âmbito Jurídico, Rio Grande, XIII, n. 72, jan 2010. Disponível em: <http://www.ambitojuridico.com.br/site/index.php?n_link=revista_artigos_leitura\&artig o_id=7039>. Acesso em mar 2016.

SILVA, Marcelo Amaral da. Digressões acerca do princípio constitucional da igualdade. Revista Jus Navigandi, Teresina, ano 8, n. 66, 1 jun. 2003. Disponível em: <https://jus.com.br/artigos/4143>. Acesso em: 12 mar. 2016.

SUNDFELD, Carlos Ari. Licitação e Contrato Administrativo. 2. ed. São Paulo: Malheiros, 1995.

ZAFFARONI, Eugenio Raúl; PIERANGELI, José Henrique. Manual de direito penal brasileiro: Volume I - Parte Geral. 9. ed. São Paulo: Revista dos Tribunais, 2011.

CO- CULPABILITY CRIMINAL GENETIC MITIGATING CIRCUMSTANCE OF ART . 66 CRIMINAL CODE 


\section{ABSTRACT}

It is presented in this paper the study on the Principle of Social co-culpability, and why this is important to ensure the effectiveness of equality principle enshrined in Article 5 of the Constitution of 1988. Finally, we will examine the possibility of co-culpability Penal be applied as genetic mitigating circumstance of art. 66 of the Brazilian Penal Code.

Keywords: Principle of Equality. Principle of social coculpability. Innominate mitigating circumstances 